\title{
The Role of Smartphones in Mediating the Touristic Experience
}

\begin{abstract}
Mobile phones have evolved to be smart computers (smartphones) supporting a wide range of information services that can be accessed anytime and from (almost) anywhere. With the increasing number of users and greater incursion into people's life, smartphones have the potential to significantly influence the touristic experience. This study explores the mediation mechanisms of smartphones by examining stories provided by travelers related to their use of smartphones (and associated applications) for traveling purposes. The results reveal that smartphones change tourists' behavior and emotional states by addressing a wide variety of information needs. Importantly, the instant information support of smartphones enables tourists to more effectively solve problems, share experiences, and 'store' memories. The implications of these findings are important in that they suggest the huge potential of smartphones in changing many aspects of the tourism business.
\end{abstract}

Keywords: Smartphone, mobile communication, touristic experience, internet 


\section{The Role of Smartphones in Mediating the Touristic Experience}

\section{INTRODUCTION}

Mobile phones have evolved in the past few years such that they have a variety of input capabilities, large screens, reliable and unlimited Internet access, and powerful location awareness function (Want 2009). Importantly, the increased capabilities of mobile phones (i.e., smartphones) support thousands of mobile applications (apps) which extend the functionality of mobile phones to a wide range of information services such as specialized information search, social networking, navigation, etc. Indeed, recent studies indicate that smartphones and their apps have the potential to assist travelers by providing easy access to information anytime and (almost) anywhere (Brown and Chalmers 2003; O’Brien and Burmeister 2003; Rasinger, Fuchs, and Hopken 2007). Further, Kramer, Modsching, Hagen, and Gretzel (2007) found that travelers' activities can be easily changed by the use of smartphones. And more recently, Tussyadiah and Fesenmaier (2009) and Wang, Park, and Fesenmaier (2010) found that smartphones can mediate both the behavioral and psychological dimensions of the touristic experience by facilitating information search, information processing, and information sharing, by enabling a traveler to learn about new travel opportunities and get to know better a destination, and by sharing photos and other 'social' activities at any time during the trip.

In order to further understand the role of smartphones in mediating the touristic experience, this study examines tourists' stories about the use of smartphones in helping their travel. The rest of this paper is organized into four sections. The next section provides a brief overview of the literature describing the conceptual foundation of the touristic experience and discusses the relationships between smartphones, tourist information needs, and touristic 
experience. The sampling and data analysis methods are described in the following section. In the results section, the mediation mechanisms are identified and illustrated in detail using ten interpretive maps of tourists' stories describing their use of travel-related smartphone apps. Last, the results are discussed focusing on future research and the marketing implications of increasingly adoption of smartphones.

\section{LITERATURE REVIEW}

Travel is a process in which tourists leave the place where they usually live and travel to different places, interact with the objects and people in those places, and document travel memories in the formats of photos and videos (Clawson 1963; Cohen 1979; Tussyiadiah and Fesenmaier 2009). Some scholars suggest that travel is a "linear" process and have defined touristic experience from a temporal perspective (Graburn 1989; Craig-Smith and French 1994; Jennings 1997, 2006) and involves three phases: 1) the anticipatory phase; 2) the experiential phase; and 3) the reflective phase (Clawson 1963; Craig-Smith and French 1994). Within these phases, tourists complete a series of activities such as information search, planning, reservation, visiting, shopping, dining, and reflection. Besides the core activities of tourism, social and environmental activities have been recognized to be important part of the overall touristic experience (Anderick, Bricker, Kerstetter, and Nickerson 2006). Therefore from the temporal perspective, the tourist experience is an "activity-based" process.

Considering that experiences are reflective and inherently personal (Holbrook and Hurschman 1982; Pine and Gilmore 1999), some scholars argue that the touristic experience lies "beyond" the temporal dimension (Jennings et al. 2009). For example, Urry (1990) introduced the concept of tourist gaze in arguing that the touristic experience is different for each individual 
because the tourist subjectively objectifies and interprets the places he/she visits. Uriely (2005) echoed this viewpoint by suggesting further that the diverse characteristics of the touristic experience can be explained by the diversity of tourist motivations. Botterill and Crompton (1996) also explored the touristic experience from individual perspective based on personal construct theory (PCT) and concluded that tourists have "idiosyncratic ways of seeing" (p. 77), and that their understanding of the touristic experience cannot be separated from travelers' psychological processes and emotional states.

The literature also indicates that travel is a sense-making process, in which travelers construct the touristic experience by learning, understanding, and feeling the places visited and the culture embedded in these places (Jennings and Weiler 2006). The places visited and cultures experienced are connected to tourists by stakeholders, including tourists, tourist providers, governments, communities and indigenous groups. As such, these stakeholders mediate the touristic experience by (mis)representing and/or being part of the tourism context. One of the well-known examples of mediators in the tourism setting is the tour guide; indeed, Cohen (1985) argues that contemporary tour guides serve a mediatory role in that they link tourists to locals (social mediation) and translate "the strangeness of a foreign culture into a cultural idiom familiar to the visitors" (p. 15) (cultural brokerage).

The development of mass media and technology enriches the meaning of mediation in tourism context. In the context of communication, mediation includes two components: (1) circulated messages and (2) the technological apparatus and media forms enabling the circulation (Lash and Friedman 1992). Tourists first get connected with the destinations/ attractions through messages circulated by the media such as film, TV, literature, magazines, and videos, which direct "tourists gaze" by constructing and reinforcing tourists' anticipation to visit places (Urry, 
1990). Based on the spatial appropriation, which is related to people's mobility in different spaces, Jansson (2002, p. 435) organized the media into a three-dimension mediascape including "symbiotic mode (i.e. documentaries, photography)", "antagonistic mode (i.e. tourism brochures, souvenirs)", and "contextual mode (i.e. sport programmes, movies)". And he further argues that different modes of mediascape induce a diversity of travel modes in the social and physical landscapes. Thus, travel becomes "a hermeneutic circle" (Lagerkvist, 2008, p. 349) in which tourists make plans before trips according to messages communicated by the media and follow the planned tracks.

The Internet, as a new media, mediates tourism at a more extended level because it provides interactive opportunities for the audience and the media. Recent studies have begun to examine the extent to which internet-based systems mediate the touristic experience (Cheverst et al. 2000; Wang, Yu, and Fesenmaier 2002; Gretzel, Fesenmaier, and O’Leary 2006; Tussyadiah and Fesenmaier 2009). For example, Tussyadiah and Fesenmaier (2009) studied the role of online shared videos in mediating the touristic experience by providing mental pleasure through stimulating fantasies and daydreams and by providing access to foreign landscapes and socioscapes with narrative transportation. They describe the mediation mechanism from the relationship between imaginative hedonism and optimal experience where they argued that "the new media as a form of cultural artifact and the potential actions inherent in it can provide a certain type of pleasurable feedback to the investment of attention, cause a certain degree of involvement and generate an enjoyable experience" (p. 27). Additionally, mobile tour guides such as CRUMPET (Poslad et al. 2001), INTRIGUE (Ardissono et al. 2003), and P-Tour (Maruyama et al. 2004) have been designed to direct tourists during their traveling by providing recommendations and visualizing the surroundings of tourists. Thus, the mobile tour guides 
enhance the "mediated gaze" (Lagerkvist 2008, p. 351) because of its ubiquitous nature. As such, the studies illustrate the mediation mechanism in the way that the media constructs the anticipations and motivations to visit places. However, the mediation mechanism in the tourism context cannot be completely understood without the consideration of the use of "media" by tourists in their travel. The new media such as the Internet has been the main tool of travel planning (Pan and Fesenmaier 2006). Tourists use the Internet to facilitate travel for different reasons originated from a variety of information needs related to knowledge, utility increase, novelty, creativity, hedonic pleasure, and social activities (Vogt and Fesenmaier 1998; Cai, Feng, and Breiter 2004; Cho and Jang 2008). The satisfaction of these information needs induce different outcomes such as destination visiting, quality experience, high overall satisfaction. Therefore, the mediation mechanism in the context of tourism requires a more profound understanding on the relationship among information needs, information tools (i.e. the Internet, Smartphones), and touristic experience.

Smartphones, as one kind of new media, now can provide a wide range of information services to support not only main travel activities such as planning, reservation, navigation, but many "micro-moments" within the travel process such as finding gas stations, estimating waiting time of rides etc (Wang, Park, and Fesenmaier 2010). Thus, travelers' information needs can be addressed anytime in the travel process including anticipatory phase, experiential phase, and reflective phase (Gretzel, Fesenmaier, and O'Leary 2006). For example, within the experiential phase (i.e., during the trip), smartphones provide access to location-based services (i.e. "destination guides" apps) can recognize the current location of tourists and provide relevant suggestions based on tourists' inquiries including restaurants, souvenir shops, gas stations and even a restroom. Thus, tourists may divert from their current route and initiate unplanned 
activities. Also, some "entertainment" apps enable tourists to plot photos onto a map immediately after photo-taking and share these photos with social networking websites. In this way, travelers can keep their friends up to date and enjoy feedback about their on-going travel experience. These evidence suggests the role of smartphones in mediating touristic experience. That is, smartphones have potential to construct the "mediated gaze" (Lagerkvist 2008, p. 351) for the tourists and create the anticipation of potential tourists through traveler's experience sharing activities (Gretzel, 2010) (See Figure 1).

Insert Figure 1 here

\section{METHODS}

Smartphones providers such as Apple, Blackberry, Verizon, AT\&T, etc. offer access to a hundreds of thousands of smartphone apps through a variety of online systems including "iTunes" for iPhones and "Market" for Android-system supported phones. In customer evaluations/reviews of the smartphone apps, many users describe how the apps they purchased (or downloaded for free) affected (positively or negatively) their travel experience. This study uses these customer reviews to examine the nature and degree to which smartphones mediate the touristic experience. The customer reviews used in this study are the ones associated with the top one hundred smartphone travel-related apps as described in Wang, Park, and Fesenmaier (2010). Specifically, they examined the travel related apps made available by Apple Inc. through iTunes, arguing that these apps are the most active ones in terms of number of users (see Table 1). Data on the use of the apps was collected through a computer program designed to "scrap" the basic information about each travel related app (e.g. release date, version, developer, function description) and customer reviews posted for that app. By the end of July, 2010, the most 
popular one hundred travel-related apps included approximately 75 percent of all customer review records $(37,133$ records out of the total 49,357 records of customer reviews under the travel category).

\section{Insert Table 1 here}

An analysis of the customer reviews indicated that most reviewers commented on the specific functions and usability of the app without describing their travel experience. However, some customer reviews included discussion of the impact of the apps on their travel experience where they offered "snapshots" of how the particular app supported or enhanced their experience. Following Craig (2007), it is argued that these reviews are "narratives" which are "the most likely medium to capture the contingencies of human experience as lived in context and over time" (p. 174). Studies in anthropology, literary theory, psychology, geography, and organizational theory also have argued that the narrative is "the closest we can come to experience" (Connelly and Clandinn 1990). Recent studies have identified the intrinsic motivations of tourists in generating online word-of-mouth (WOM) such as self-expression, selfdiscovery, solving problems (Pan, MacLaurin, and Crotts, 2007; Gretzel and Yoo 2008; Bronner and de Hoog 2010). These findings suggest that online WOM (i.e. customer reviews) can provide important and useful information in describing touristic experience. Thus, it is posited that these storytelling customer reviews are extremely helpful in exploring the role of smartphone apps in mediating touristic experiences.

The screening process for identifying storytelling customer reviews began by examining all reviews (37,133 records) in terms of their content and length measured by the number of 
words. First, short reviews (e.g., reviews that include 100 words or less - a total 25,383 records), were eliminated as they focused solely on the functions of the apps and/or provided general feelings about the apps such as "love", "amazing", "disappointing," of which provides little information about the impact of the apps on their travel experience. Second, negative reviews (with the rating 1 or $2,10,831$ records representing $29 \%$ of the total) were eliminated as preliminary analysis indicated that they too focused solely on usability-related aspects of the apps. This two-step screening process resulted in 919 customer reviews that were considered potential storytelling customer reviews. A third step in the screening process involved two of the authors wherein they conducted a manual screening of reviews was based on the storytelling degree-of-freedom instrument (see Table 2) proposed by Woodside, Sood, and Miller (2008). Specifically, they read the reviews separately to look for "stories" describing of the use of the apps and their role in the travel experience. It was decided that if five of the seven criteria proposed by Woodside et al (2008) were met, the customer review was kept as a viable storytelling customer review. Based upon this process, 202 out of 919 customer reviews (22\%) were classified as the storytelling customer reviews. Although 202 reviews only represent around 0.5 percent of total review records $(37,133)$, it is argued that they provide sufficient insight to address the overall goal of this study, which is to explore the impact of smartphones (and their apps) on the touristic experience. Table 3 summaries the screening process used in this study.

Insert Table 2 and 3 here

Content analysis was then used to analyze the selected customer reviews. Content analysis is a "research technique for the objective, systematic, and quantitative description of the 
manifest content of communication" (Berelson 1952, p. 18). There are two general classes of content analysis in social science: qualitative and quantitative. Qualitative content analysis refers to non-statistical and exploratory methods which are often an epistemology whereby "reality" is a social and cultural creation which can be accessed only by the detailed investigation (Berg 2001). Quantitative content analysis, on the other hand, refers to methods that are capable of classifying many words of text into much fewer content categories which then can be counted for their occurrences and provide statistical inferences from text populations (Weber 1990). The selection of quantitative and qualitative content analysis depends on the purpose of study and styles of textual data (e.g. appropriate for summarization, similarity of different files, etc.) (Newbold, Boyd-Barrett, and Van Den Bulck 2002). Thus, it is argued that qualitative content analysis is the most appropriate approach given that the goal of this study is to explore the mediation of smartphones on the touristic experience from customer reviews (Neuendorf 2002).

The 202 qualified customer reviews were manually assessed/coded using two sets of codes: information needs and the outcomes of the use of smartphones (see Table 4). The information needs codes were initially developed based on the typology proposed by Vogt and Fesenmaier (1998) as they included both functional and psychological dimensions of information search. The codes related to outcomes, on the other hand, were grounded in the customer reviews. Specifically, the development of codes was an iterative process whereby the initial code list was developed based upon the literature and then revised during the process of analysis; importantly, the two coders worked separately for coding and inter-coder reliability was checked by calculating Krippendorff (1980)'s alpha. For two sets of codes (information needs and outcomes), the Krippendorff's alpha for each set of codes is around 0.7 ( 0.77 for the information needs, and 0.69 for the outcomes), which is the threshold for inter-coder reliability (Krippendorff 
1980).

Insert Table 4 here

Analysis of the co-occurrence of information needs, outcomes and the categories of apps was examined using crosstab analysis. Then following Woodside and Chebat (2001), deconstructive analysis was used to assess how (the nature and extent) smartphones affect the travel experience by identifying representative customer reviews from each group of information needs. Specifically, each review was deconstructed by developing an emic narrative interpretation map with the application of approach for story analysis in order to understand the protagonist's activities and emotions, and the relationship between protagonist and other key concepts within the travel experience such as other people or objects.

\section{RESULTS}

Table 5 presents the extent to which smartphone apps address the information needs and their induced outcomes. As can be seen, all five information needs proposed by Vogt and Fesenmaier (1998) were mentioned by tourists in the reviews. As one might expect, functional information needs are most frequently described (164 cases, $81 \%)$. The second frequently mentioned information need relates to social information (44 cases, $22 \%$ ), which is followed by hedonic information needs (33 cases, 16\%), innovation information needs (18 cases, 9\%), and aesthetic information needs (14 cases, 7\%). Satisfaction in meeting these information needs appear to have had fourteen different outcomes varying from behavior to emotional states. About one quarter of the travelers described how the smartphone apps help them to get a "good value" out of their trips (53 cases, 26\%), become more "efficient" in terms of planning and activities (40 cases, 
$20 \%$ ), and improve their overall satisfaction (36 cases, 18\%). Ten percent of travelers indicated that the use of smartphone apps added "delight to their trips" (23 cases, 11\%), helped them to "meet their expectation" (20 cases, 10\%), and eliminated their stress and worries ("peaceful mind", 19 cases, 9\%). Three to six percent of the reviewers described a variety of other benefits including providing a "rich experience" (13 cases, 6\%), "inspiration for travel" (12 cases, 6\%), "life saver" (11 cases, 5\%), "show off_self esteem" (11 cases, 5\%), "share happiness" (9 cases, 4\%), "confidence" (7 cases, 3\%), and "visit more places" (6 cases, 3\%).

\section{Insert Table 5 here}

The Relationships of Smartphone Apps, Information needs, and the Outcomes of the Use of Apps

In the following paragraphs, the relationships between apps and information needs, apps and outcomes, and information needs and outcomes are described based on the results of crosstab analysis. Table 6 presents the results of a crosstab analysis of information needs and different categories of smartphone apps $\left(\chi^{2}=153.389, p<.000\right)$. It appears that functional information needs are highly associated with the apps of "Flight Information Management" (Category 8, 32.7\%) and "Attractions Guides" (Category 11, 17.8\%). Innovation information needs are more likely to be associated with the apps of "Food Finder" (Category 3, 4.5\%) and "Destination Guides" (Category 9, 3.5\%). The "Attractions Guides" apps (Category 11, 6.9\%) appear to address hedonic information needs. Social information needs are more likely to be addressed by the "Flight Information Management" apps (Category 8, 7.4\%) and "Attractions Guides" apps (Category 11, 9.5\%). Finally, the aesthetic information needs are addressed mainly by “Attraction Guides” apps (Category 11, 5.4\%). 
Insert Table 6 here

Different categories of apps are associated with different outcomes due to their distinctive capability in addressing information needs. Table 6 also presents the results of a crosstab of the outcomes induced by the satisfaction of information needs and different categories of smartphone apps $\left(\chi^{2}=327.627, p<.000\right)$. "Attractions Guides" apps (Category 11) are identified to be the most influential apps because this category of apps is highly associated with seven outcomes (highest percentage in each row) including overall satisfaction (7.9\%), good value (10\%), delight the trip (6.4\%), meet expectation (4.5\%), efficiency (3.5\%), inspiration for travel (3\%), and share happiness (2\%). "Flight Information Manager" apps (Category 8) are more likely being able to bring easy life (9.5\%), solutions (life saver) $(2.5 \%)$, and peaceful mind $(9.5 \%)$ for tourists. "Food Finder" apps (Category 3) can add value (good value) (4\%) to the trips. Finally, "Destination Guides" apps (Category 9) are able to encourage tourists to visit more places during the trips $(2 \%)$.

In this study, it also appears that the outcomes of apps use raise by information needs. Figure 2 displays the association between information needs and the outcomes where the cooccurrence are based on the Jaccard's coefficients (Cheetham and Hazel 1969) (the coefficients are computed from a fourfold table as $a /(a+b+c)$ where $a$ represents cases where both items occur, and $b$ and $c$ represent cases where one item is found but not the other). The results of this analysis indicates the strongest association is between "Aesthetic information needs" and "Inspiration for travel", followed by "Innovation information needs" and "Rich experience"; "Functional information needs" and "Good value"; "Hedonic information needs" and "Delight 
the trip"; and "Social information needs" and "Peaceful mind". In addition, satisfaction related to social information needs is associated with efficiency in the trip; satisfaction related to functional information needs is associated with improving overall satisfaction, and satisfaction related to hedonic information needs may induce shared happiness. Last, satisfaction related to innovation information needs encourage tourists to visit more places.

Insert Figure 2 here

\section{Narrative Interpretation of the Touristic Experience Influenced by Smartphones}

The stories provided by tourists can provide for a vivid understanding on the mediation mechanisms of smartphones in the touristic experience. This section presents a series of travelers' reviews which reflect different ways (scenarios) travelers have used the respective applications and their impact on their travel experiences. The scenarios are organized based on the typology of information needs. In particularly, tourists' stories in each scenario were selected considering its representativeness of other stories which reveal the relationships between the apps, information needs in that how they are addressed, and the outcomes of the use. As a result, two customer reviews are deconstructed for each scenario into emic narrative interpretation map to display the touristic experience following Woodside and Chebat (2001) and Woodside, Cruickshank, and Dehuang (2007).

\section{Scenario I: Good value and Efficiency}

The dynamic and intangible nature of travel process makes it difficult for tourists to predict all of situations and then make plans to maximize benefits. For example, accidents 
happened during a trip can easily ruin the whole vacation. Also, the unpredictable situations may limit tourists in following the original plan. Therefore, during the trip tourists may need extra information in order to cope with the unpredictable situations. Thus, instant access to information support maybe important in addressing emergent information needs. Importantly, meeting with these information needs may improve the efficiency in the travel process and maximize the value of the trip. In the following two scenarios, smartphones mediated touristic experience by awarding tourists "a smooth travel experience" and "maximizing the travel experience".

This scenario represents around 44 percent (90 cases) of storytelling customer reviews $(\mathrm{N}=202)$ which yet have different contexts but reflect the nature of using the apps to add value. Figure 3, for example, presents a story about how the app "Flight update pro" facilitated the protagonists (Case 226) in the multi-flight transition process. The protagonist was traveling with his wife on a multi-stop flight and they were delayed at an intermediate destination, which may have lead to missing a subsequent flight if they could not find the connecting gate in the shortest time. With the app "Flight update pro", the protagonist was able to "immediately find the right terminal" and to avoid "wait over 6 hours for the next flight". As a result, the protagonist felt "traveling is under control" and had "a smooth experience". Figure 4 presents a second story about how the app "Lines" helped the protagonist (Case 69) to do instant on-site planning while visiting the Walt Disney World (WDW). As can be seen, the app "Lines" helped the traveler to get updated information about the waiting time for each ride in that he/ she could figure out most efficient plan in the park. The result is that the protagonists felt that they had a "valued" trip.

Insert Figure $3 \& 4$ here 


\section{Scenario II: Visiting More Places and Having Rich Experiences}

Tourists like "surprises" in the travel process because the unexpected activities may bring extra happiness to tourists, therefore, tourists keep looking for new and adventurous experiences (Snepenger 1987). In order to reduce the risk embedded in the adventurous experiences, tourists need information to support decision-making, as showed in the following scenario, smartphones stimulate tourists to change activities and take adventures by providing instant information support. These storytelling customer reviews including 11 cases (5\% of total 202 cases) whereby tourists describe their experience in which the smartphone apps lead them to learn, to re-plan, and to visit new places and/or attractions. As illustrated in Figure 5, the traveler (Case 577) extended his/her road trip because the "Roadside America" app lead him/her to "places I might never have experienced or heard". As a result, the protagonist felt that "the app enhanced my trip a thousand fold from what it would have been like with only maps and travel guides."

Insert Figure 5 here

Also, touristic experience may be enriched by the availability of a variety of options. Due to the intangibility of travel products, tourists get to know their products by the time of consumption. Tourists gradually change their plan if it does not match with the actual experience. Thus, tourists need information on a variety of options. Smartphones help tourists in this perspective by providing suggestions based on tourists' preferences and assisting tourists to personalize the search results. For example, Figure 6 is a story about a frequent traveler. As most of other frequent travelers, the protagonist (Case 534) was tired of the local food in the 
destination he/she visited several times (within a month). He/she "can only handle so much 'Paula Dean'-type choices" and wanted to have a different taste. The "Open table" app helped him/her find "the places the locals did not know existed", which turn out a feeling that the app "delights the boring trips".

Insert Figure 6 here

Scenario III: A Delightful Trip and Higher Satisfaction

Tourists are hedonic pleasure seekers for fun, enjoyment, amusement, and sensory stimulation. The information services provided by smartphones appear to elicit tourists' hedonic pleasures by providing novel information. "Delightful trip" and "higher satisfaction" are two most frequently mentioned outcomes of using the apps (10\%, 21 cases of total 202 cases). For example, the "Air Traffic Control" app helps tourists to listen to the conversation among crews and aviation control staff. Such novel information eases the boredom of tourists in the waiting time in the airport. As illustrated in Figure 7, the protagonist (Case 476) indicated that the "Air Traffic Control" app can make the long and weary waiting time at the airport fun and enjoying. Also, the protagonist perceived that the app is "both entertainment and comfort" for a nervous flyer because he/she can know that "the plane and the ground are working together". In addition, the storytelling customer reviews show that the mobile apps can help tourists recognize the hedonic aspects of experience, which leads to higher overall satisfaction. Figure 8 presents the story of the app that can award tourists more fun when they were able to make postcard and share with friends right after taking photo on-the-spot. The protagonist (Case 568) would like to share her travel experience with family and friends in the form of postcard, but she hated to shop local postcards and send in the post office. The "Postman" app enabled her to share the "fabulous 
sunset" with her husband in the format of a self-made postcard, as a result, the protagonist really enjoyed the trip (particularly the sunset) because of the unique experience co-created by the app.

Insert Figure $7 \& 8$ here

\section{Scenario IV: Sharing Happiness, Showing Off, and a Peaceful mind}

Many of the storytelling customer reviews reveal that smartphones delight the trips by enabling tourists to connect with not only families, but also new friends during the trip. The following three scenarios illustrate the outcomes of smartphones using social media apps and represent about 13 percent of the total storytelling customer reviews ( 26 cases). By providing a platform for an online community, smartphones can connect tourists who are visiting the same destination/attraction and looking for similar information. Such "portable" online communities enriched tourist experience in many ways. For example, the smartphones can convert a virtual relationship to be a real relationship. Therefore, members of a online community in the same destination/attraction can meet each other (in reality). Figure 9 illustrates the influence of mobile online community where the protagonist (Case 146) visited the Disneyland with his/her friends and they wanted more people to join their group for fun. With the "MouseWait" app, they got connected with other tourists in the park at that time and they finally met in the park to have fun together. The protagonist had a better experience in Disneyland than he/she expected as he/she felt that the helpful app made Disneyland "the happiest place on earth".

Also, the advantages brought by smartphones in instant information accessing can make tourists feel special in a group. For example, the smartphone users can earn appreciation from other people in public by providing information (Figure 10). The protagonist (case 330) had a delayed flight when he/she was in a trip from Portland coming back to his/her home. When 
he/she was using the app "Flight Status" to check the incoming plane on the map, other passengers waiting for the same flight were "impressed at the level of detail on the map". It was turned out that "about 20 plus people look at this (the app) on my iPad". The protagonist was very proud that he/she can say "the plane should be landing before the agent at the gate announcing it". In this story, the protagonist's trip was delighted by the use of smartphone because the appreciation from others made he/ she feel "really good".

In addition, the ease of information sharing enabled by the smartphone apps helped tourists to keep their families, friends and even themselves informed. As a result, the updated information eliminated the worries and concerns caused by the uncertainty of travel process. Figure 11 presents a story (Case 723) that a traveler used the app "tripIt" to manage his complicate travel schedules and share the information with his wife, which resulted in "a sigh of relief" for this tourist because he won't be confused by the itineraries and "a peaceful mind" for his wife because she could know his husband's schedules.

Insert Figures $9 \& 10 \& 11$ here

\section{Scenario V: Inspiration for Travel}

Aesthetic consumption is an interesting part of tourism consumption (Vogt and Fesenmaier 1998). Unlike functional needs, the nature of aesthetic needs is intangible and selfevoked (Hirschman 1983). Tourists are attracted to places or attractions by the aesthetics of their natural environment, cultural phenomenon, or artificial arts. Smartphone apps can provide information to help the construction of the imagery of destinations and attractions. Thus, smartphone apps can help to address travelers' aesthetic information need and inspire people to travel more. In this study, 5 percent of the total storytelling customer reviews (9 cases) somehow 
reflect this benefit of smartphone use. For example, figure 11 presents a story about a person using the "American Treasures" app and the inspiration it provided for the protagonist to travel. The protagonist used the app to get to know the places during his/her trip and he/she acquire new knowledge about new destinations nearby the places that the protagonist arrived. In this way, the protagonist kept learning during the trip and was "inspired" to plan another trip.

Insert Figure 12 here

\section{DISCUSSION}

Customer reviews of smartphone apps provide "snapshots" of the touristic experience and analysis of these reviews reveals how their use mediates touristic experience by changing tourists' behavior and emotional states. The results of this study indicate that tourists benefit substantially from the use of smartphone apps by providing "smoother" and more "delightful" experiences. More specifically, the reviews show that smartphone apps mediate touristic experience by addressing a range of information needs. First, the smartphone apps enable tourists to cope with unexpected situations ("life saver", "easy life", "peaceful mind”) and to complete travel activities efficiently and effectively ("good value, "efficiency", "meet expectations") by meeting functional information needs. Tourists then can stick to their plans and satisfy their anticipation. Second, some smartphone apps award tourists surprises ("delight the trip", "visit more places"), excitement ("rich experience"), imagination ("inspiration for travel") and even a sense of achievement (“confidence", "show off_self esteem”) by addressing tourists' information needs for innovation, hedonic pleasure, aesthetics and social activities. These finding confirm that smartphones can be a powerful tool in intensify travelers' interests in the travel process. 
The implications of these findings are clear from a tourism marketing perspective in that smartphones and the huge variety of apps offer very important marketing opportunities for tourism organizations. For example, the ubiquity and strong computation capability of smartphones encourage tourists' unplanned (impulsive) activities. Many tourists use the apps with the "near me" function to get to know their environment and try new activities. Therefore, location-based marketing becomes even more important for businesses such as restaurants, attractions, and shops which, in turn, means that new strategies need to be developed whereby business embed advertisements into the search results of the apps providing such services. Also, the results of the study indicate that the smartphones can be a powerful tool to enhance the onsite touristic experience. For example, the stories about how Disneyland apps helped visitors at the theme park suggest they (the tourists) actually rely upon the apps to coordinate and interpret their activities (i.e., experiences), suggest that smartphone apps offer a huge new arena for virtualization of tourism businesses. An important addition to this finding is that smartphones are seen as a portable platform for social communities which can encourage/facilitate opportunities for interaction among tourists. Indeed, this study shows that such instant interactions with other tourists who are traveling in the same places and sharing the same interests are one of the sources of satisfying touristic experience. This finding suggests that tourism businesses such as theme parks, destination marketing organizations can use mobile supported social media in much more creative ways to improve the touristic experience. Finally, the challenge for tourism businesses is not only to develop smartphone apps to improve touristic experience, but also it is important that they develop strategies (including adding internal capacities) that encourage the adoption of the apps. While this point may seem to be a "nobrainer," studies show that the capacity to innovate is one of the most important challenges 
for tourism businesses.

It is apparent that the increasing penetration of mobile devices in people's daily life will have a profound influence on how people think and behave. Therefore it is posited that these changes in daily life will lead to significant changes in travel behavior as the unique features of the travel context (i.e. out of home, search for new experiences, and unpredictability) may encourage travelers to rely even more on mobile devices. The implications of these changes are significant and suggest two important streams of future research. The first stream of research should focus on the influence of mobile devices specifically on travel planning. Due to ubiquitous nature of mobile devices and the incredible depth and breadth of innovation of mobile apps, travelers may change information channels by substituting other digital devices (i.e. video recorder, mp3 players, etc.), and as a result, travelers' decision-making schema may change dramatically. The second area of research focuses on the interaction of travelers' use of information services available on mobile devices and the development of information services (i.e. apps for mobile devices). The penetration of mobile information services in people's life may induce greater use of mobile information services in the travel context, which in turn, may result in important changes in the relationships between travelers, the destinations they visit and the experiences (the stories) the create. 


\section{References}

Anckar, B., and D. D'Incau (2002). "Value creation in mobile commerce: Findings from a consumer survey." The Journal of Information Technology Theory and Application, 4 (1): 43-64.

Andereck, K., K. S., Bricker, D. Kerstetter, and N. P. Nickerson (2006). In Quality Tourism Experiences, edited by G. Jennings and N. P. Nickerson, Oxford: Elsevier ButterworthHeinemann, pp. 81-98.

Ardissono, L., A. Goy, G. Petrone, M. Segnan, and P. Torasso (2003). "Intrigue: Personalized recommendation of tourist attractions for desktop and hand held devices." Applied Artificial Intelligence, 17 (8): 687-714.

Assael, H. (1984). Consumer Behavior and Marketing Action. Boston: Kent.

Berelson, B. (1952). Content Analysis in Communication Research. New York, NY: Hafner Publishing.

Berg, B. L. (2001). Qualitative Research Methods for the Social Sciences. Boston: Allyn \& Bacon.

Botterill, T. D., and J. L. Crompton (1996). "Two case studies exploring the nature of the tourist's experience.” Journal of Leisure Research, 28 (1): 57-82.

Bronner, F., and R. de Hoog (2011). "Vacationers and eWOM: Who posts and why, where, and what?" Journal of Travel Research, 50 (1): 15-26.

Brown,B. , and M. Chalmers (2003). "Tourism and mobile technology". In Proceedings of the eighth conference on European Conference on Computer Supported Cooperative Work, 335-354. Helsinki, Finland: Kluwer Academic Publishers.

Cheverst, K., N. Davies, K. Mitchell, A. Friday, and C. Efstratiou (2000). "Developing a context-aware electronic tourist guide: some issues and experiences." In Proceedings of the SIGCHI conference on Human factors in computing systems, New York, NY, USA: ACM, pp. 17-24

Cai, L., R. Feng, and D. Breiter (2004). "Tourist purchase decision involvement and information preferences." Journal of Vacation Marketing, 10 (2): 138 -148.

Cho, M., and S. Jang. (2008). "Information value structure for vacation travel." Journal of Travel Research, 47 (1): 72-83.

Cheetham, A. H., and J. E. Hazel (1969). "Binary (presence-absence) similarity coefficients." Journal of Paleontology, 43 (5): 1130-1136. 
Clawson, M. (1963). Land and Water for Recreation: Opportunities, Problems and Policies. Chicago: Rand Mc Nally.

Cohen, E. (1979). A Phenomenology of Tourist Experiences. Harper Perennial.

Cohen, E. (1985). “The tourist guide: The origins, structure and dynamics of a role." Annals of Tourism Research, 12 (1): 5-29.

Craig, C. J. (2007). "Story constellations: A narrative approach to contextualizing teachers' knowledge of school reform." Teaching and Teacher Education, 23 (2): 173-188.

Craig-Smith, S., and C. French. (1994). Learning to Live with Tourism. Melbourne: Pitman.

Engel, J. F., D. T. Kollat, and R. D. Blackwell (1978). Consumer Behavior. New York: Dryden.

Gretzel, U., D. R. Fesenmaier, and J. T. O'Leary (2006). “The transformation of consumer behavior." In Tourism Business Frontier, edited by D.Buhalis and C. Costa, Oxford, UK: Elsevier, pp. 9-18.

Gretzel, U., and K. Yoo (2008). "Use and impact of online travel reviews." In Information and Communication Technologies in Tourism, edited by P. O'Connor, W. Hopken, and U. Gretzel, Wien, New York: Springer-Verlag, pp. 35-46.

Gretzel, U. (2010). Travel in the Network: Redirected Gazes, Ubiquitous Connections and New Frontiers. In Levina, M., \& Kien, G. (Eds.). Post-global Network and Everyday Life (pp. 41-58). New York: Peter Lang.

Graburn, N. (1989). “Tourism: The sacred journey.” In Hosts and Guests: The Anthropology of Tourism, edited by V. Smith, Philadelphia: University of Pennsylvania, pp. 21-36.

Holbrook, M. B, and E. C Hirschman (1982). "The experiential aspects of consumption: Consumer fantasies, feelings, and fun." Journal of consumer research, 9 (2): 132-140.

Howard, J. A., and J. N. Sheth (1969). The Theory of Buyer Behavior. New York: Wiley.

Jansson, A. (2002). "Spatial phantasmagoria: The mediatization of tourism experience." European Journal of Communication, 17(4): 429-443.

Jennings, G. R. (1997). “The travel experience of cruisers.” In Pacific Rim 2000: Issues, Interrelations, Inhibitors, edited by M. Oppermann, London: CAB International, pp. 94105.

Jennings, G. R. (2006). "Perceptions on quality tourism experience.” In Quality Tourism Experiences, edited by G. Jennings and N. P. Nickerson, Oxford: Elsevier ButterworthHeinemann, pp. 1-22. 
Jennings, G. R., and B. Weiler (2006). "Mediating meaning: Perspectives on brokering quality tourism experiences." In Quality Tourism Experiences, edited by G. Jennings and N. P. Nickerson, Oxford: Elsevier Butterworth-Heinemann, pp. 57-78.

Jennings, G. R., Y. Lee, A. Ayling, B. Lunny, C. Cater, and C. Ollenburg (2009). “ Quality tourism experiences: Reviews, reflections, research agendas." Journal of Hospitality Marketing \& Management, 18 (2): 294-310.

Kramer, R., M. Modsching, K. Hagen, and U. Gretzel (2007). "Behavioural impacts of mobile tour guides." Information and Communication Technologies in Tourism 2007: 109-118.

Krippendorff, K. (1980). Content Analysis: An Introduction to Its Methodology. Newbury Park, CA: Sage.

Lagerkvist, A. (2008). "Travels in thirdspace: Experiential suspense in mediaspace - the case of America (Un)known.” European Journal of Communication, 23 (3): 343-363.

Leiper, N. (1979). "The framework of tourism: Towards a definition of tourism, tourist, and the tourist industry". Annals of Tourism Research, 6 (4): 390-407.

Maruyama, A., N. Shibata, Y. Murata, K. Yasumoto, and M. Ito (2004). "P-tour: A personal navigation system for tourism." In Proc. of 11th World Congress on ITS, 2:18-21.

Mills, J. E, and R. Law. 2005. Handbook of consumer behavior, tourism, and the Internet. Routledge.

Neuendorf, K. A. (2002). The Content Analysis Guidebook. Thousand Oaks, CA: Sage.

Newbold, C., O. Boyd-Barrett, and H. Van den Bulck. (2002). The media book. London: Arnold.

O’Brien, P., and J. Burmeister (2003). "Ubiquitous travel service delivery". Information Technology \& Tourism, 5(4): 221-233.

Pan, B., T. MacLaurin, and J. C. Crotts (2007). "Travel blogs and the implications for destination marketing." Journal of Travel Research, 46 (1): 35-45.

Pine, B. J., and J. H. Gilmore (1999). The Experience Economy: Work is Theater and Every Business a Stage. Boston: Harvard Business School Press.

Poslad, S., H. Laamanen, R. Malaka, A. Nick, P. Buckle, and A. Zipf (2001). "CRUMPET: Creation of user-friendly mobile services personalised for tourism." In Proceedings of the Second International Conference on 3G Mobile Communication Technologies, pp. 26-29.

Rasinger, J., M. Fuchs, and W. Hopken (2007). "Information search with mobile tourist guides: A survey of usage intention." Information Technology \& Tourism, 9(3-4): 177-194. 
Snepenger, D. (1987). "Segmenting the vacation market by novelty-seeing role." Journal of Travel Research, 26 (2): 8-14.

Tussyadiah, I. P., and D. R. Fesenmaier (2009). "Mediating tourist experiences: Access to places via shared videos." Annals of Tourism Research, 36 (1): 24-40.

Tussyadiah, I. P., and D. R. Fesenmaier (2008). "Marketing places through first-person stories an analysis of Pennsylvania roadtripper blog." Journal of Travel \& Tourism Marketing, 25 (3): 299-311.

Uriely, N. (2005). The tourist experience: Conceptual developments. Annals of Tourism Research, 32: 199-216.

Urry, J. (1990). The Tourist Gaze. London: SAGE Publication.

Vogt, C. A., and D. R. Fesenmaier (1998). "Expanding the functional information search model." Annals of Tourism Research, 25 (3): 551-578.

Woodside, A. G., and J. C. Chebat (2001). “Updating Heider's balance theory in consumer behavior: A Jewish couple buys a German car and additional buying-consuming transformation stories." Psychology \& Marketing, 18 (5): 475-495.

Woodside, A. G., and C. Dubelaar (2002). "A general theory of tourism consumption systems: A conceptual framework and an empirical exploration." Journal of Travel Research, 41 (2): $120-132$.

Woodside, A. G., B. F. Cruickshank, and N. Dehuang (2007). "Stories visitors tell about Italian cities as destination icons." Tourism Management, 28 (1): 162-174.

Woodside, A. G., S. Sood, and K. R. Miller (2008). "When consumers and brands talk: Storytelling theory and research in psychology and marketing." Psychology and Marketing, 25 (2): 97-145.

Wang, D, S. Park, and D. R. Fesenmaier (2010). "An examination of information services and smartphone applications." Proceedings of 16th Annual Graduate Student Research Conference in Hospitality and Tourism, Houston, TX, USA.

Wang, Y., Q. Yu, and D. R. Fesenmaier (2002). "Defining the virtual tourist community: Implications for tourism marketing. Tourism Management, 23 (4): 407-417.

Want, R. (2009). "When cell phones become computers". Pervasive Computing, IEEE, 8(2): 2-5. 
Table 1. The categories of smartphone apps based on the types of information services

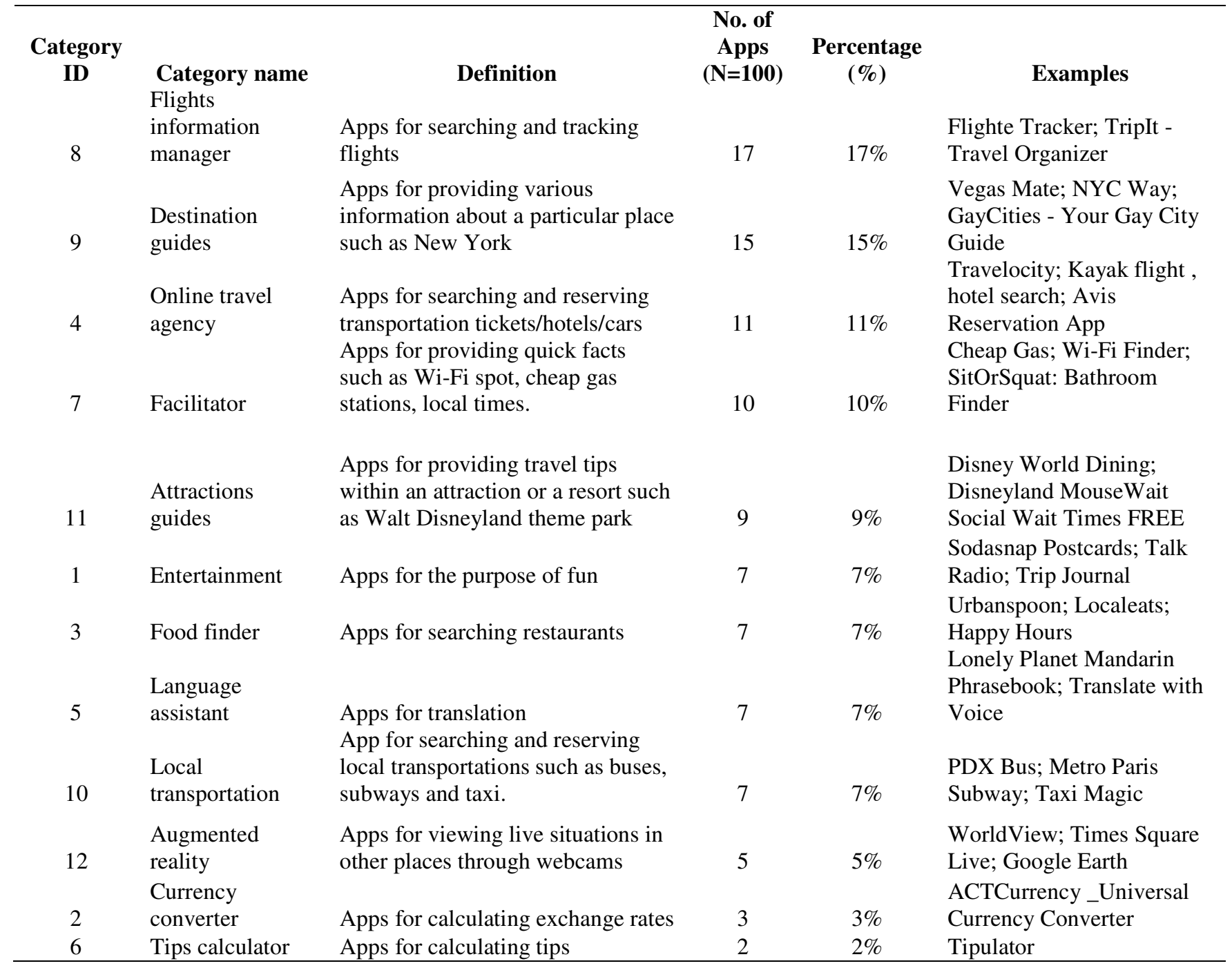


Table 2. Storytelling degree-of-freedom instrument (adapted from Woodside, Sood, and Miller 2008, p.116)

For each proposition below, please circle one response regarding

No Not sure Yes

whether the proposition matches the storytelling format:

1. Protagonist found in the customer reviews engages in actions to achieve goals?

2. Mundane presentation of self in everyday life of a protagonist in the story

3. Protagonist found in reviews engages in actions to achieve goals?

4. The review presents a story that informs about conscious and /or unconscious thoughts of the protagonist and other actors?

5. The review describes a world or personal block that does/may prevent goal attainment?

6 . The review has a beginning, middle, and end?

7. The review presents a protagonist in the clear-cut situations? 
Table 3. The screening process and screening criteria for the storytelling customer reviews

\begin{tabular}{ll}
\hline \multicolumn{1}{c}{ Screening process } & \multicolumn{1}{c}{$\begin{array}{c}\text { Screening criteria } \\
\text { All reviews }\end{array}$} \\
$\begin{array}{ll}\text { Total 37,133 customer reviews for } 100 \text { apps were } \\
\text { "scraped" from iTune app store }\end{array}$ \\
$\begin{array}{l}\text { 26,302 positive customer reviews (reviews with rating } 4 \\
\text { or 5) are selected because the purpose of this study is to } \\
\text { examine how the apps can help or facilitate tourists. }\end{array}$ \\
$\begin{array}{l}\text { Candidates of storytelling } \\
\text { reviews }\end{array}$ & $\begin{array}{l}919 \text { positive customer reviews are selected based on the } \\
\text { length (equal or greater than 100 words). The short } \\
\text { positive reviews cannot reveal the touristic experience }\end{array}$ \\
Storytelling reviews & $\begin{array}{l}\text { 202 records are identified as storytelling customer } \\
\text { reviews based on the storytelling degree-of-freedom } \\
\text { instrument (Woodside, Sood, and Miller 2008). }\end{array}$ \\
\hline
\end{tabular}


Table 4. Code book

\section{Information needs}

I. Functional information needs

II. Innovation information needs

III. Hedonic information needs

IV. Aesthetic information needs

VI. Social information needs

\section{Outcomes}

a. Overall satisfaction

b. Good value

c. Confidence

d. Easy life

e. Life saver

f. Rich experience

g. Delight the trip

h. Meet expectation

i. Efficiency

j. Show off_self-esteem

$\mathrm{k}$. Inspiration for travel

1. Share happiness

m. Peaceful mind

n. Visit more places
Definition (Adapted from Vogt \& Fesenmaier, 1998, p. 570)

Tourists need information to learn, increase the value of the trip, improve efficiency, reduce uncertainty, and release stress.

Tourists need information to be innovative, look for different things, plan new things for trips.

Tourists need information to be excited, "feel" the destination, and experience the local cultural and life.

Tourists need information to imagine destinations, and form expectations Tourists need information to give advices to others, share their experience, and be valuable for their friends.

Definitions (grounded from customer reviews)

"a great trip", "fantastic experience", etc.

"maximize my experience"; "really add value", etc

"no worry about anything"; "I' $m$ the expert of....", etc.

"relief"; "no stress"; "easy life", etc.

"life saver", "save my life", "save my marriage", etc.

"enriched my experience", "experienced a lot", etc.

"delightful experience"; "delighted my trip", etc.

"as we planned", "exactly as I expected", etc.

"efficient planning", "find my gate in a minute", etc.

"I impressed other people", "my friends depend on my decision"; etc.

"miss Disney so much", "looking forward our next road trip", etc.

"put miki's smile on my mom's face", etc.

"release my nerve", "peace in mind"; etc

"went to many places which we don't even know without it"; etc. 
Table 5. Frequency of information needs and outcomes

\begin{tabular}{lcc}
\hline \hline Info. Needs & Cases & \% Cases (N=202) \\
\hline I_Functional & 164 & $81 \%$ \\
IV_Social & 44 & $22 \%$ \\
III_Hedonic & 33 & $16 \%$ \\
II_Innovation & 18 & $9 \%$ \\
VI_Aesthetic & 14 & $7 \%$ \\
\hline Total codes frequency & 273 & \\
\hline \hline Outcomes & Cases & \% Cases (N=202) \\
\hline b_Good value & 53 & $26 \%$ \\
i_Efficiency & 40 & $20 \%$ \\
a_Overall satisfaction & 36 & $18 \%$ \\
d_Easy life & 25 & $12 \%$ \\
g_Delight the trip & 23 & $11 \%$ \\
h_Meet expectation & 20 & $10 \%$ \\
m_Peaceful mind & 19 & $9 \%$ \\
f_Rich experience & 13 & $6 \%$ \\
k_Inspiration for travel & 12 & $6 \%$ \\
e_Life saver & 11 & $5 \%$ \\
j_Show off_self esteem & 11 & $5 \%$ \\
1_Share happiness & 9 & $4 \%$ \\
c_Confidence & 7 & $3 \%$ \\
n_Visit more places & 6 & $3 \%$ \\
\hline Total codes frequency & 285 & \\
\hline \hline
\end{tabular}


Table 6. Crosstab of smartphone apps, information needs, and the outcomes of the satisfaction of information needs.

Smartphone Apps by Categories (\% of cases, $\mathrm{N}=202$ )

\begin{tabular}{|c|c|c|c|c|c|c|c|c|c|c|c|c|}
\hline Info. Needs & 1 & 2 & 3 & 4 & 5 & 6 & 7 & 8 & 9 & 10 & 11 & 12 \\
\hline I_Functional & 1.5 & 0.5 & 5.4 & 3.0 & 1.0 & 0.5 & 7.4 & 32.7 & 5.0 & 5.9 & 17.8 & 0.5 \\
\hline II_Innovation & & & 4.5 & & & & 0.5 & & 3.5 & & 0.5 & \\
\hline III_Hedonic & 1.0 & & 3.0 & & & 0.5 & 0.5 & 1.5 & 2.0 & & 6.9 & 1.0 \\
\hline IV_Social & 1.5 & & 1.0 & 0.5 & 0.5 & & 0.5 & 7.4 & 0.5 & 0.5 & 9.5 & \\
\hline VI_Aesthetic & & & & & & & & & & & 5.4 & 1.5 \\
\hline Outcomes & 1 & 2 & 3 & 4 & 5 & 6 & 7 & 8 & 9 & 1 & 11 & 12 \\
\hline a_Overall satisfaction & 1.0 & & 2.5 & & 0.5 & & 1.0 & 1.5 & 2.5 & 1.0 & 7.9 & \\
\hline b_Good value & 0.5 & & 4.0 & 1.5 & & 0.5 & 3.5 & 3.5 & 2.5 & 0.5 & 10.0 & \\
\hline c_Confidence & & & 1.0 & & & & 1.0 & 1.0 & & 0.5 & & \\
\hline d_Easy life & & 0.5 & 0.5 & 0.5 & & & 1.0 & 9.5 & & & 0.5 & \\
\hline e_Life saver & & & 0.5 & & & & & 2.5 & 0.5 & 1.5 & 0.5 & \\
\hline f_Rich experience & & & 2.5 & & & & & & 1.5 & & 2.5 & \\
\hline g_Delight the trip & 1.0 & & 1.5 & & 0.5 & 0.5 & 0.5 & 0.5 & 0.5 & & 6.4 & \\
\hline h_Meet expectation & & & 0.5 & & & & 0.5 & 3.5 & & 0.5 & 4.5 & 0.5 \\
\hline i_Efficiency & 0.5 & & & 0.5 & 0.5 & & 2.0 & 1.9 & 0.5 & 1.5 & 3.5 & \\
\hline j_Show off_self esteem & & & 0.5 & & & & 0.5 & 2.5 & & 0.5 & 1.5 & \\
\hline $\mathrm{k} \_$Inspiration for travel & & & 0.5 & & & & & & 0.5 & & 3.0 & 2.0 \\
\hline 1_Share happiness & 1.0 & & 0.5 & & & & & 0.5 & 0.5 & & 2.0 & \\
\hline m_Peaceful mind & & & & & & & & 9.5 & & & & \\
\hline n_Visit more places & & & & & & & & & 2.0 & & 0.5 & 0.5 \\
\hline
\end{tabular}

Note:

$1=$ Entertainment; $2=$ Currency converter; $3=$ Food finder; $4=$ Online travel agency;

$5=$ Language assistant; $6=$ Tips calculator; $7=$ Facilitator; $8=$ Flights information manager;

$9=$ Destination guides; $10=$ Local transportation; $11=$ Attractions guides; $12=$ Augmented reality 


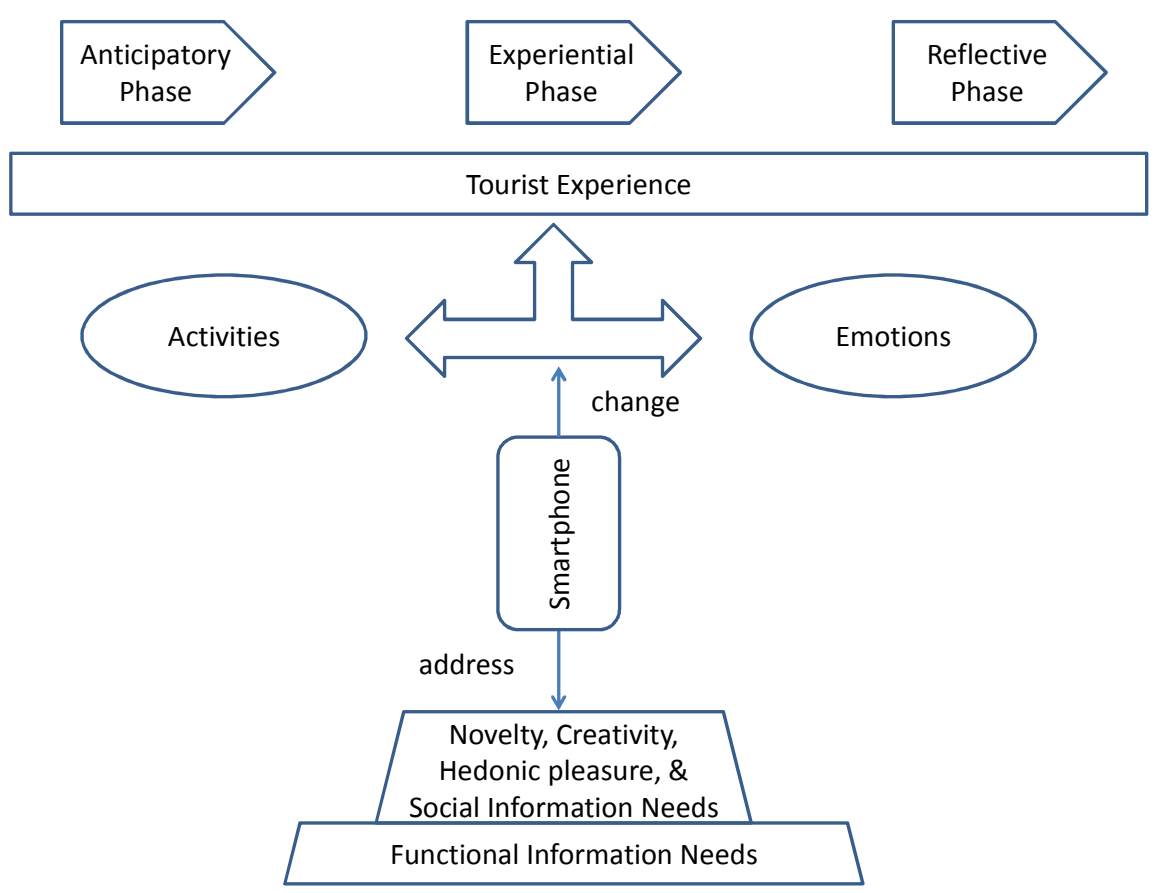

Figure 1. Mediation mechanism of smartphones in touristic experience 


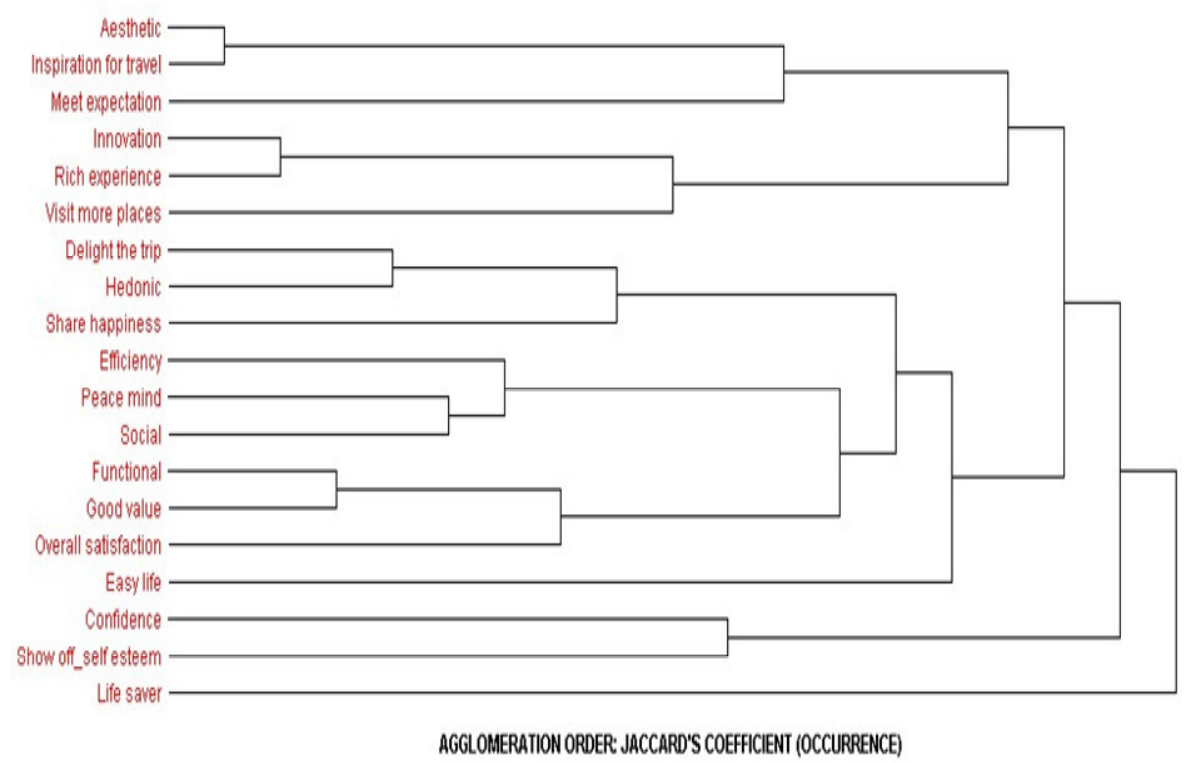

Figure 2. Clustering of information needs and outcomes 


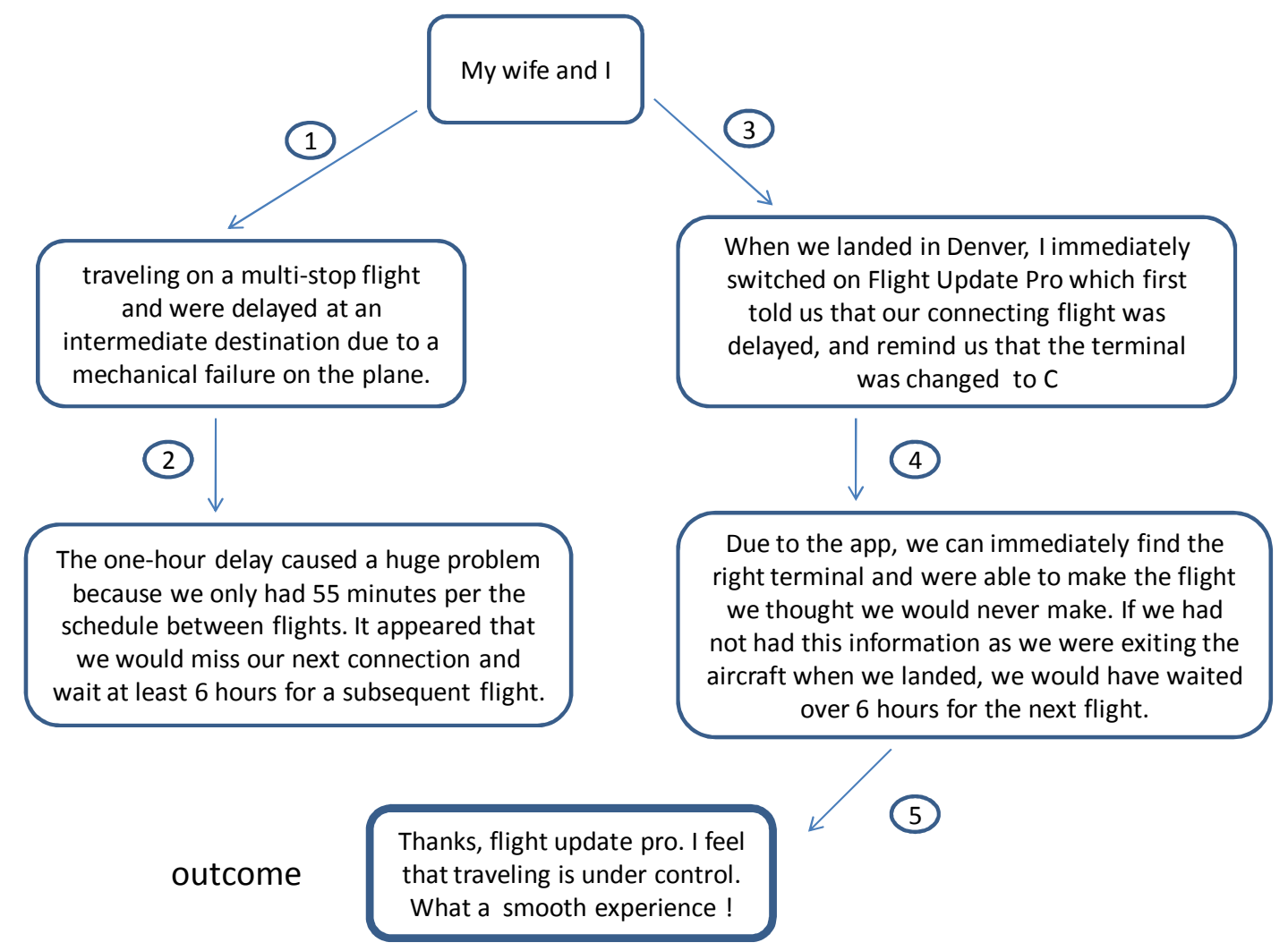

Figure 3. Tourist's story about the smartphone app "Flight Update Pro" and the "efficiency" 


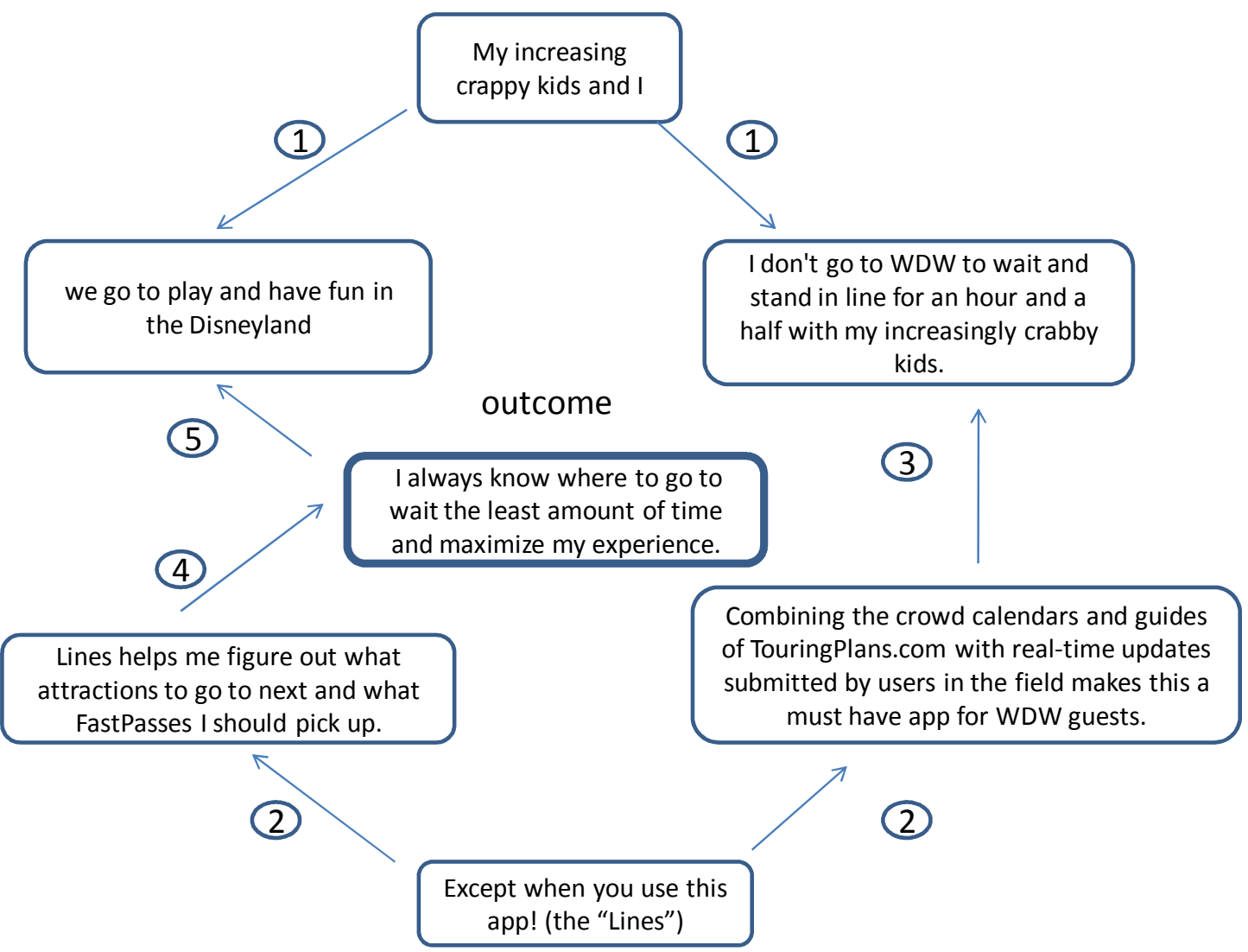

Figure 4. Tourist's story about the smartphone app "Lines" and the "good value" 


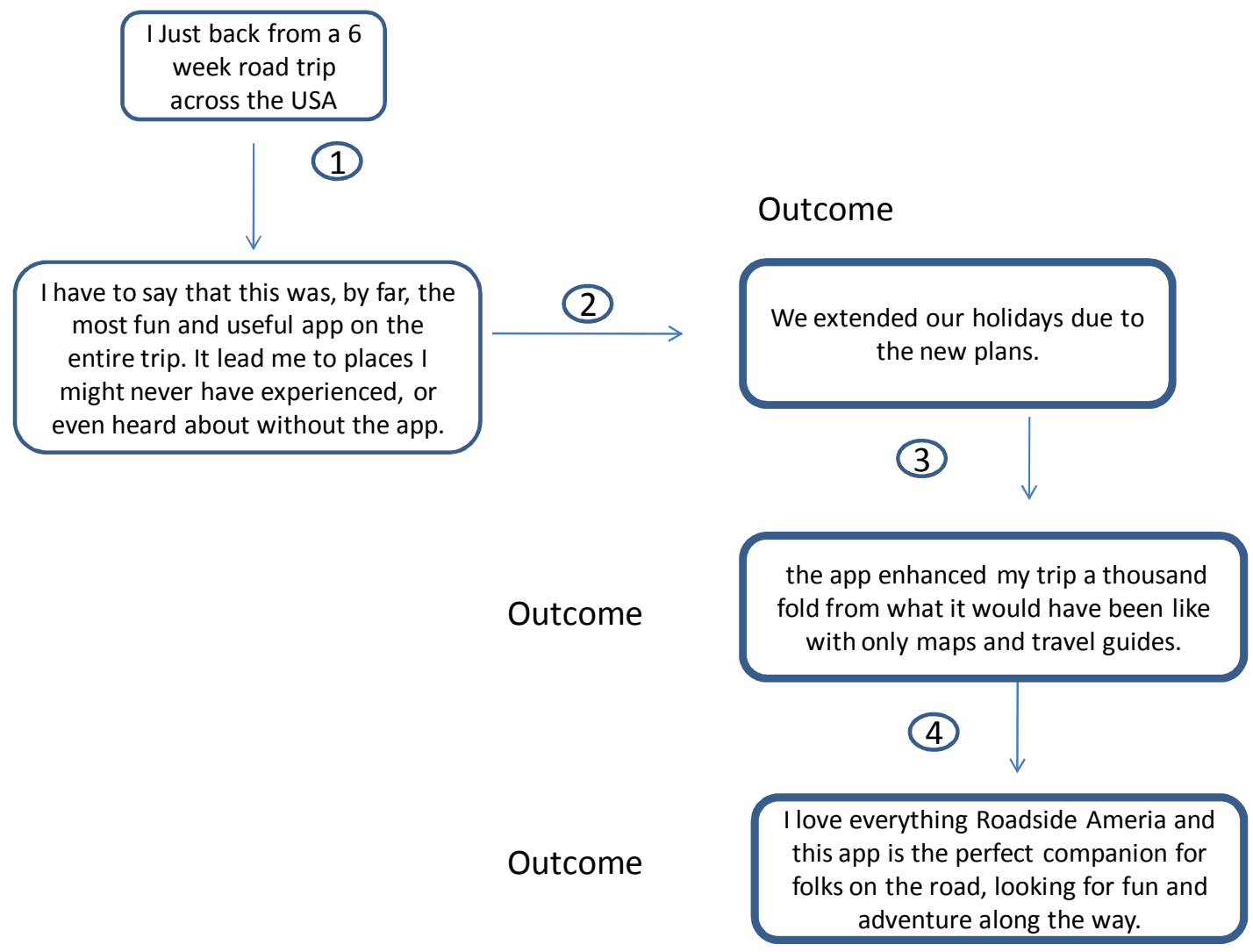

Figure 5. Tourist's story about the smartphone app "Roadside America" and the "visit more places" 
Last year I had to do a LOT of traveling for business and found myself in both metropolitan and small southern towns.

\section{(1)}

As with most people, I can love the southern theme like the best of them, but when it comes to food -

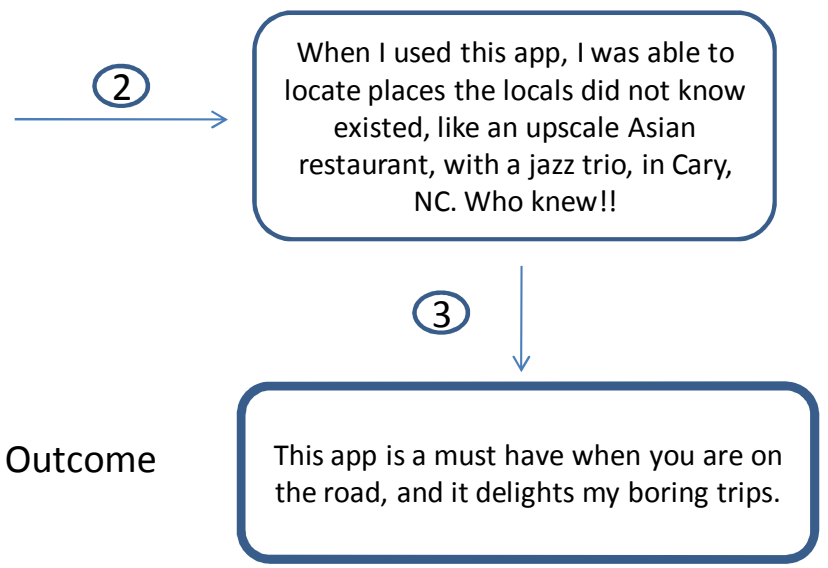

Figure 6. Tourist's story about the smartphone app "Open table" and the "rich experience" 
(4)

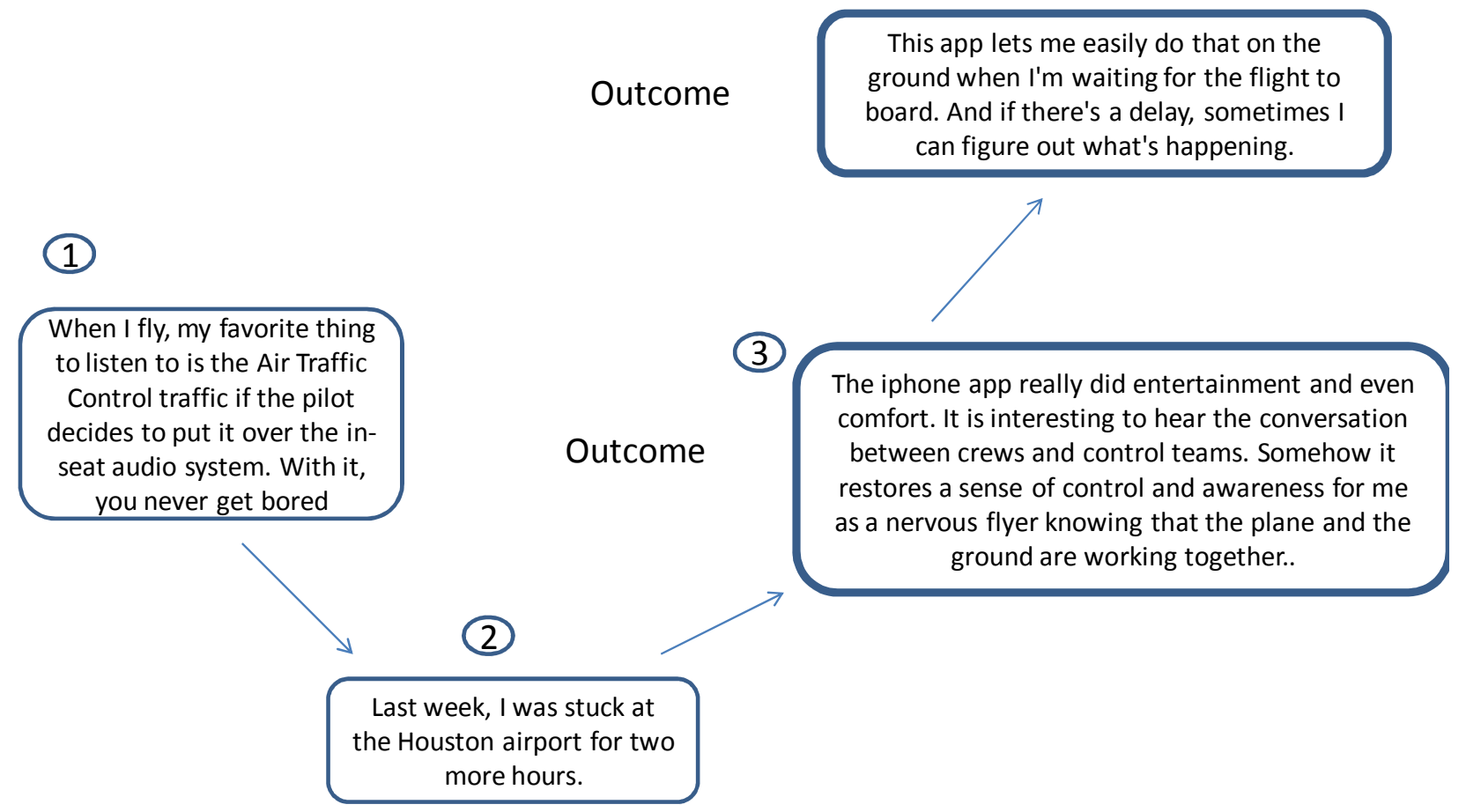

Figure 7. Tourist's story about the smartphone app "Air Traffic Control" and the "delightful trip" 
For two years now I've been waiting for a program that allows me to send a postcard to my family and friends without shopping for a postcard that

(1) someone else offers.

\section{Outcome}

That's the most beautiful sunset in my mind.
I just hate taking time from my busy schedule and shopping for a postcard that will do from the rack and then find a stamp from all the stamps I've purchased in the last few years from the Post Office.

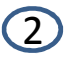

NOW, it doesn't matter and is very easy to do with this app. I tried it in my trip to San Francisco.

(4)

The sunset golden gate is just fabulous. I want to show my hubby. The app helped me to polish my photo right away to be a romantic postcard.

Figure 8. Tourist's story about the smartphone app "Postman" and the "higher satisfaction" 


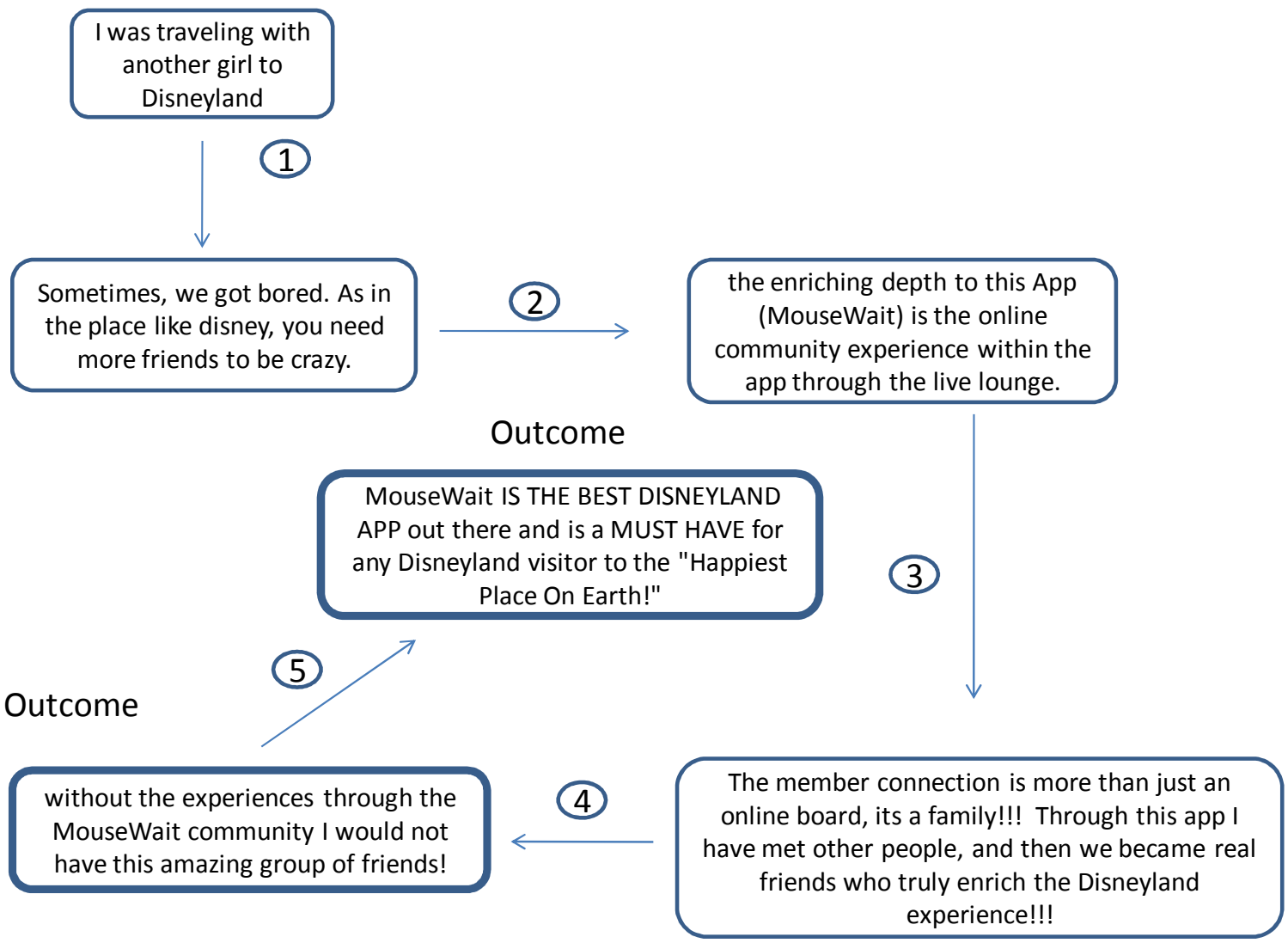

Figure 9. Tourist's story about the smartphone app "MouseWait" and the "Share happiness" 
One person wanted to see my Ipad and what I was looking at (again, this app). That person was impressed at the level of detail on the map and proceeded to tell another person, who then told another and before you knew it, I had about 20 plus people look at this on my lpad. They were truly impressed when I said the plane should be

(1)

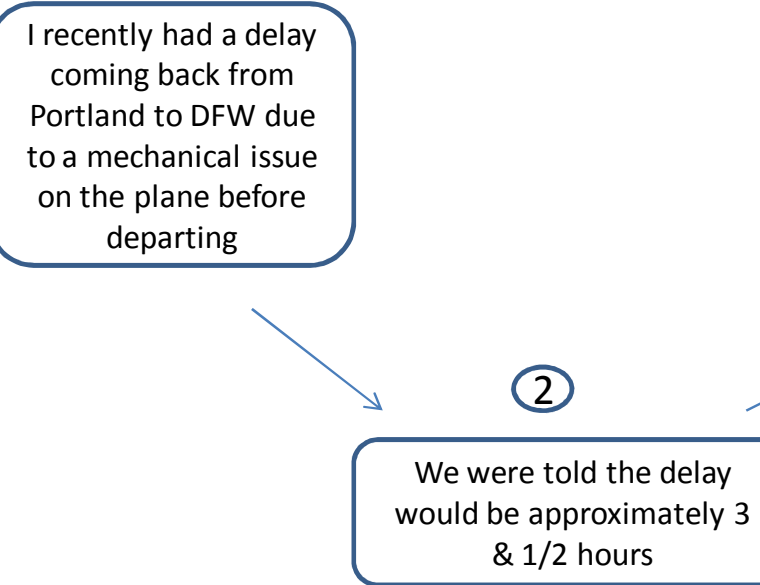

Figure 10. Tourist's story about the smartphone app "Flight Status" and the "Show off" 
(1)

$$
\begin{aligned}
& \text { I'm going on an } 11 \text { day trip to Hawaii } \\
& \text { and I'm visiting } 3 \text { islands. With } 5 \text { flights } \\
& \text { on } 5 \text { different days and hotels and car } \\
& \text { rentals, my email inbox was a mess and I } \\
& \text { was dreading creating my own itinerary. }
\end{aligned}
$$

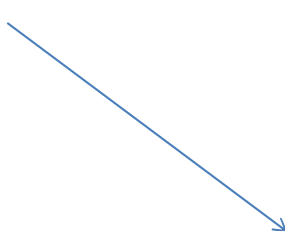

I found Triplt and I breathed a sigh of relief. Within minutes everything was saved in a chronological

(by date and hours) itinerary with all the details I needed. Also, you can even share your trips with your family. I know that my wife, nervous every time I travel, will have a peaceful mind by knowing my complicate itinerary.

Figure 11. Tourist's story about the smartphone app "TripIt" and the "Peaceful mind" 


\section{Outcome}

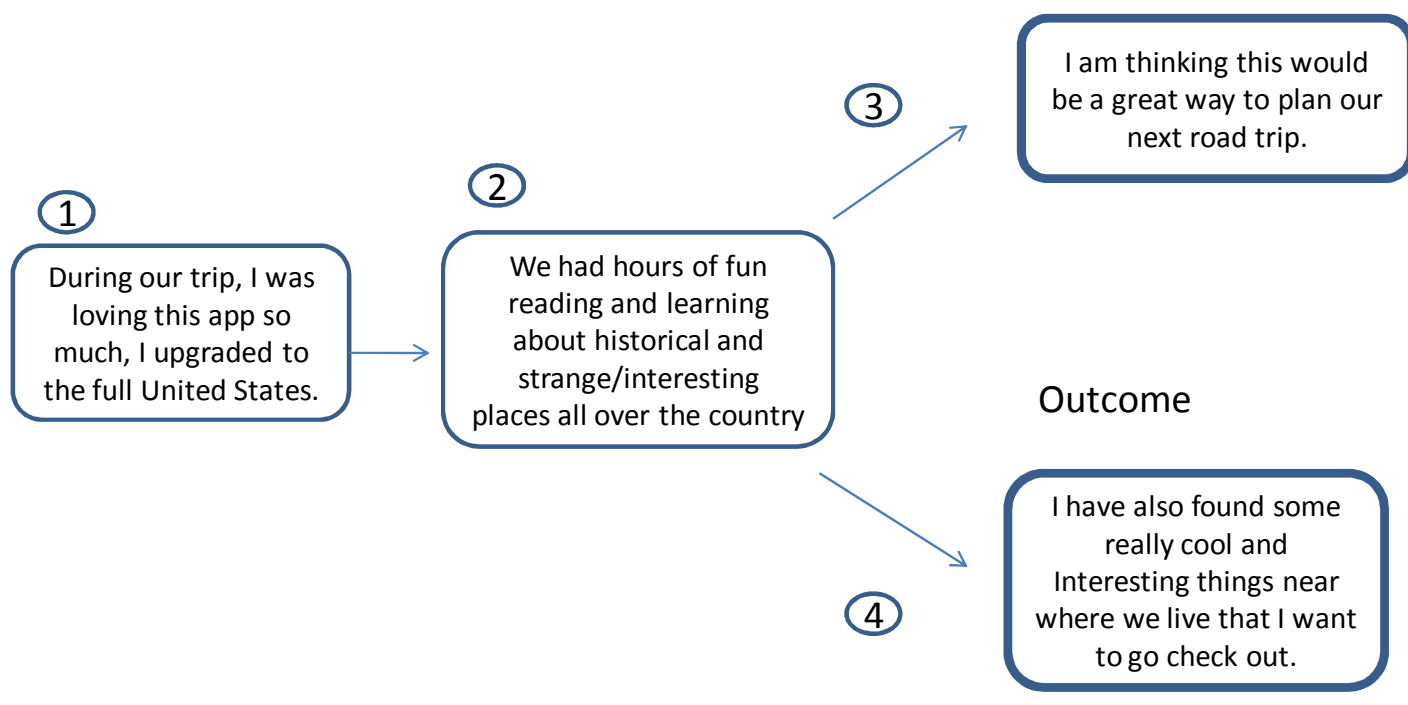

Figure 12. Tourist's story about the smartphone app "American Treasures" and the "Inspiration for travel" 